\title{
CONTRIBUIÇÕES DE MARTIN HEIDEGGER PARA A COMPREENSÃO FENOMENOLÓGICA-EXISTENCIAL DO ESPAÇO
}

\author{
Maria Lucivane de Oliveira Morais ${ }^{1}$
}

\begin{abstract}
RESUMO: Esse artigo trata da contribuição e críticas de Martin Heidegger ao pensamento que se ocupa de tratar do espaço. No $\$ 22$ da obra Ser e tempo, encontram-se elementos que possibilitam a crítica às concepções produzidas pelas ontologias regionais que o tratam apenas por meio de dimensões físicas, métricas, delineadas pela técnica, pelas transformações históricas promovidas pelo ser-aí, etc. Ao mesmo tempo, por meio de sua fenomenologia, permite compreender existencialmente o espaço como o campo de jogo do ser-no-mundo que somos e este ser-no-mundo como o ente que se lança para múltiplas possibilidades do seu existir, fornecendo-nos os subsídios necessários para o delineamento de uma reflexão pautada em bases fenomenológico-existenciais. O problema que orientou as discussões apresentadas a seguir visa responder brevemente: Como a fenomenologia existencial de Heidegger contribui para pensar o espaço? A metodologia empregada baseou-se em análises bibliográficas de Ser e tempo, pesquisa em artigos e livros diversos cujos autores de dedicaram a análise da fenomenologia heideggeriana, sobre espaço com base no pensamento tradicional e fenomenológico-existencial.
\end{abstract}

Palavras-chave: Espaço. Heidegger. Ser-aí. Fenomenologia.

\section{CONTRIBUTIONS OF MARTIN HEIDEGGER TO THE PHENOMENOLOGICAL- EXISTENTIAL UNDERSTANDING OF SPACE}

\begin{abstract}
This article deals with the contribution and criticism of Martin Heidegger to the thought that deals with dealing with space. In $\$ 22$ of the book Being and Time, there are elements that allow the critique of the conceptions produced by the regional ontologies that treat it only by means of physical dimensions, metric, delineated by the technique, by the historical transformations promoted by being-there, etc. At the same time, through its phenomenology, it allows us to existentially understand space as the playing field of the being-in-the world that we are and this being-in-the-world as the entity that launches into the multiple possibilities of its existence, We need the necessary subsidies for the delineation of a reflection based on phenomenological-existential bases. The problem that guided the following discussion aims to respond briefly: How does Heidegger's existential phenomenology contribute to space thinking? The methodology used was based on bibliographical analyzes of Being and time, research in articles and diverse books whose authors dedicated the analysis of Heideggerian phenomenology, on space based on the traditional and phenomenological-existential thinking.
\end{abstract}

Keywords: Space. Heidegger. Be-there. Phenomenology.

\footnotetext{
${ }^{1}$ Mestranda em Filosofia Moderna e Contemporânea na Universidade Estadual do Oeste do Paraná UNIOESTE. Contato: maria lucivane@ hotmail.com
} 


\section{INTRODUÇÃO}

A obra Ser e tempo de Martin Heidegger, foi publicada no ano de 1927, possibilitando a retomada da pergunta pelo sentido do ser que fora esquecida e/ou tratada de maneira inadequada pela tradição metafísica. Suas análises possibilitaram a construção de uma ontologia fundamental embasada em dois subprojetos: analítica existencial e hermenêutica da facticidade.

Dentre as temáticas abordadas cita-se a análise ontológica do espaço que irá perpassar suas várias obras sem que, no entanto, tenha sido objeto de interesse de uma reflexão específica. No $\$ 22$ se encontra uma importante crítica sobre as compreensões elaboradas pelas ontologias regionais sobre o espaço e sua definição como um ente constituído por propriedades que o permitem quantificá-lo, medir, transformá-lo, dentre outras ações objetivas, imediatas e utilitárias.

Estas compreensões do espaço se situam no plano ôntico, entretanto, o que Heidegger busca é a construção de um pensamento ontológico, por isso, o coloca no plano ontológico-existencial, definindo-lhe como uma estrutura existencial do ser-aí que o experimenta fenomenalmente (na forma de espacialidade), afinal o ser-aí é no mundo, ou seja, um ser-no-mundo dotado pelo caráter de possibilidade que imediatamente e de maneira abrupta é lançado no "aí" do mundo, tendo seu projeto existencial delimitado por sua atitude em relação ao espaço.

A justificativa para o delineamento de reflexões pautadas na fenomenologia de Heidegger provém de minha necessidade de compreender melhor como essa obra contribui com os estudos desenvolvidos pelas ontologias regionais especialmente, a Geografia, na qual o espaço é corriqueiramente tratado. É importante frisar que não se pretende esgotar tais análises, tampouco tecer respostas definitivas sobre essa temática que há séculos intriga pesquisadores, filósofos, geógrafos e outros interessados.

Dentre os resultados obtidos, destaca-se que Heidegger nos possibilita pensar o espaço por meio de uma experiência fenomenológica-existencial, promovendo avanços para além dos estudos ônticos produzidos que permanecem a um passo da experiência ontológica fundamental do espaço.

\section{PROJETO FILOSÓFICO HEIDEGGERIANO}


Antes de se discutir propriamente a problemática do espaço, faz-se necessário compreender alguns aspectos gerais da fenomenologia heideggeriana, tarefa que foi dedicada a esse primeiro subitem.

O filósofo alemão Martin Heidegger considerado um dos mais importantes do século XX, dedicou sua obra Ser e tempo à reabilitação da questão do ser, afirmando que ela fora tratada de maneira inadequada e/ou insuficiente ao longo da tradição metafísica e acabou sendo esquecida em virtude das afirmações de que o ser é o conceito mais universal, indefinível e evidente por si mesmo a fim de desmotivar qualquer retomada da temática.

Esta afirmação nos permite ver que a ontologia tradicional se esqueceu do ser do ente, tomando equivocadamente o ente pelo ser e vice versa, sem com isso alcançar uma experiência ontológica originária. Ao se dispor a superar tais limites recolocando a questão do sentido do ser, Heidegger produziu uma ontologia fundamental que questiona o caráter ontológico do ser, liberando-o de seu velamento ou obstrução, alcançando a "verdade do ser" e não apenas a verdade do ente como a ontologia tradicional houvera realizado (PASQUÁ, 2015)

Tal interpretação é apresentada no capítulo inicial de Ser e Tempo em seu §1:

\footnotetext{
E o que outrora se arrancou, num supremo esforço de pensamento, ainda que de modo fragmentado e tateante aos fenômenos, encontra-se, de há muito, trivializado. E não só isso. No solo da arrancada grega para interpretar o ser, formou-se um dogma que não apenas declara supérflua a questão sobre o sentido do ser, como lhe sanciona a falta.

[...] o que, num sentido extraordinário, se mantém velado ou volta novamente a encobrir-se ou ainda só se mostra "distorcido", não é este ou aquele ente, mas o ser dos entes. $\mathrm{O}$ ser pode encobrir-se tão profundamente que chega a ser esquecido, e a questão do ser e de seu sentido se ausentam. O que, portanto, num sentido privilegiado e em seu conteúdo mais próprio, exige tornar-se o fenômeno é o que a fenomenologia tematicamente tomou em suas "garras" como objeto. (HEIDEGGER, 2013, p.75).
}

Portanto, para Heidegger era evidente que a ontologia tradicional tratou o ser como um ente simplesmente dado, constituído por determinações ônticas, com definições pré determinadas ficando a um passo da experiência ontológica fundamental, pois a compreensão do ser estava voltada ao ente implicando em um erro metodológico, culminando em uma não tematização suficiente sobre a interpretação do sentido e conteúdo do ser.

O processo de destruição da ontologia tradicional era necessário para que o ser do ser-aí fosse desvelado ou liberado de suas obstruções ressurgindo na medida em que fossem questionados o "ser do ente, o ente, o sentido do ser". Aos olhos do filósofo, a fenomenologia 
seria a possibilidade necessária para superar essa problemática porque se direciona àquilo que o ente vela e encobre naturalmente: seu ser.

Para tanto, o ser-aí deverá ser interrogado antes de qualquer outro ente, permitindo a compreensão da questão do ser, que abrange três primados: “ôntico - apenas existe; ontológico - ao existir ele compreende o ser; ôntico-ontológico - é condição de possibilidade de todas as ontologias" (FRANCK, 1998, p.24).

O método fenomenológico possibilitou a contraposição necessária entre o ser e o ente, dando origem a ontologia fundamental que, apoiou-se em dois subprojetos distintos, mas complementares: a hermenêutica da facticidade e a analítica existencial que conjuntamente possibilitaram a análise do ser-aí, esse ente que somos nós mesmos cuja essência está em ter de ser e em sua existência permeada por múltiplos modos de ser em mundo dotado de possibilidades (HEIDEGGER, 2003).

O ser-aí é desde sempre lançado de maneira abrupta no espaço, sem que tenha qualquer determinação natural e enquanto ser histórico tem no mundo sua orientação, por isso, a expressão ser-no-mundo aponta para uma rede significados articulados que, por sua vez, dão sentido à existência, absorvendo-o em uma rede pré-compreensões que orientam os possíveis e diferentes modos de ser.

A hermenêutica da facticidade possibilita o esclarecimento sobre o modo como compreendemos e questionamos o sentido do ser, permitindo abordar, interrogar e explicitar a existência do ser-aí que é compreendida apenas a partir de si mesma. Desse modo, torna acessível o próprio ser-aí levando-o a sua compreensão por ser feito para e pelo próprio ser-aí que permanece em busca de sua autocompreensão (SARAMAGO, 2008).

A analítica existencial, por sua vez, pode ser compreendida como a via de acesso à questão do ser, tornando acessível o ser-aí que mantém uma “compreensão imprópria de si mesmo, dos outros e do mundo. O ente que nós somos está, a maior parte das vezes, exilado do seu ser próprio, de tal modo que nos é revelado a distância” (FRANCK, 1998, p.25).

O que está em jogo na analítica existencial, é o ente que compreende ser a partir dos traços ontológico-existenciais, ou seja, o ente que somos. A existência permite-lhe compreender o que ele é. Os momentos diversos de seu modo de ser são apontados pela análise fenomenológica como "existenciais" definidos como estruturas ontológicas que se constituem na própria dinâmica da existência. Dessa forma, "primeiro analisa suficientemente o ser-aí e depois avança na questão do ser - etapa preparatória para uma ontologia fundamental" (KAHLMEYER-MERTENS, 2015, p.76). 
Para melhor compreender o modo como o ser-aí existe no mundo, ou seja, como serno-mundo, foram tecidas as considerações seguintes a fim de preparar as reflexões sobre a íntima relação entre espaço, mundo, ser-aí e existência.

\section{O ESPAÇO E SEU ENTENDIMENTO TRADICIONAL}

A compreensão ôntica do espaço realizada ontologias regionais como, por exemplo, a Geografia, têm produzido nos últimos séculos inúmeros estudos científicos a fim de melhor compreendê-lo, descrevendo sua dinâmica, o modo como é habitado dentre outros elementos constitutivos importantes, entretanto, continuam a vê-lo apenas como um ente digno de investigação permanecendo a um passo da experiência ontológico-existencial.

Os modelos físico-descritivo e de espaço habitado tratam-lhe por meio de um caráter utilitário e imediato, fundamental para a efetivação da existência, sendo apenas uma mera base física, com definições rígidas que velam a compreensão de seu sentido fundamental, a maneira como o ser-aí delineia sua cotidianidade mediana, dentre outros aspectos presentes em seu projeto existencial atribuindo sentido a sua lida cotidiana (SARAMAGO, 2008).

Quando o espaço é tratado de forma desvinculada do ser-aí, difunde-se uma reflexão superficial, ou seja, derivada pautada no plano ôntico, incapaz de ilustrar a relação que permeia a cotidianidade do ser-aí e o espaço que lhe é constitutivo e fundamental (BOLLNOW, 2008).

Em Ser e tempo, Heidegger (2013, p.110) afirma que a visão tradicional de espaço corrobora para a produção de estudos que simplesmente elencam:

[...] tudo o que se dá no mundo: casas, árvores, homens, montes, estrelas. Podemos relatar a "configuração" desses entes e contar o que neles e com eles ocorre. Mas é evidente que tudo isso permanecerá um "ofício" pré-fenomenológico que, do ponto de vista fenomenológico, não pode ser relevante. A descrição fica presa aos entes, é ôntica. O que, porém se procura é o ser. Em sentido fenomenológico determinou-se a estrutura formal do fenômeno como o que mostra enquanto ser e estrutura do ser.

Nesse sentido, o estudo fenomenológico-existencial do espaço ultrapassa essa visão no qual os fenômenos estão simplesmente dispostos no espaço territorial que toma para si os homens, suas técnicas e domínios. Permite que percebamos as relações, vínculos afetivos, e experiências que dão sentido aquilo que ser-aí põe a mostra em sua cotidianidade e projeto existencial. 
Essa redução a uma extensão física permite à razão compreender o espaço por meio de relações ideais de proximidade, distância, de orientação, formas de ocupação, reflexo do capital, dos recursos disponíveis ao seres-aí que o modelam, etc. Desse modo, como destaca Casanova (2017, p.222):

Ao dizer, por exemplo, que um objeto se encontra a direita, à frente a 45 graus, a 100 metros de distância ou mesmo a duas horas de carro em um movimento retilíneo uniforme a $80 \mathrm{~km} /$ hora, o que estou dizendo agora é que o espaço pode ser pensado a partir de tais dimensões, uma vez que a extensão permite a localização ideal dos pontos (corpos) no interior da assíntota espacial.

Tal descrição aponta para o fato de que os entes estão simplesmente posicionados no espaço, havendo uma ordem interna que os organiza e permite o deslocamento do ser-aí caracterizando um aspecto comum em sua cotidianidade, contudo, o movimento espacializante não é considerado pela sensibilidade em suas formas pura e apriori. Este espaço é simplesmente "mapeável, ordenável, quantificável, territorializado empiricamente, por uma ciência de fatos positivamente estabelecida", portanto, se mostra como investigável segundo os princípios, por exemplo, “de circulação das pessoas e de escoamento de produtos ou de urbanização em sintonia com as necessidades oriundas do aumento vertiginoso, da população no interior das grandes cidades" (CASANOVA, 2017, p.233).

Em meio a tais considerações, a noção afetiva e fenomenológica-existencial do espaço é esquecida, assim como o fato de que não há espaço para fora do ser-aí, tampouco categorias e modos de construção capazes de ilustrar a dinâmica originária e espacializante oriunda do processo de existir. Todos nós temos nossos modos de ser no espaço que dependem fundamentalmente do modo como o espacializamos no campo existencial. Afirma-se também que:

O espaço da geometria pura, por exemplo, que não interessa a Heidegger, é um espaço que, pode-se dizer, destituído de temporalidade. Não haveria, para Heidegger, um espaço objetivamente apreensível de forma isolada das circunstâncias da vida fática do ser-aí.

[...] a ideia de espaço está atrelada aos objetivos que o tornam perceptível como localidade familiar e habitável, não podendo o espaço sequer ser concebido fora do fechamento da referencialidade do mundo, de sua familiaridade e confiabilidade específicas. [...] enquanto ser-no-mundo, o ser-aí já descobriu a cada passo um "mundo" (SILVA, 2007, p.127. 
Para Heidegger não há um "espaço previamente dado ou constituído, que poderia ser pensado em suas determinações aprioristicamente ideais, mas todo espaço depende do modo como a dinâmica de espacialização e temporização da existência acontece" (CASANOVA, 2017, p.242). Como resultado disso, instaura-se uma nova noção de espaço, que será discutida no subitem seguinte.

\section{COMPREENSÃO FENOMENOLÓGICA-EXISTENCIAL DO ESPAÇO}

Encontramos no $\S 12$ de Ser e tempo a expressão ser-no-mundo cunhada por Heidegger para ilustrar uma base mínima que representa a mais elementar e indivisível estrutura na qual o ser-aí se assenta e pode ser explicado, afinal sempre projeta-se para o mundo. Ser-aí e mundo compõem a mesma realidade que os liga ontológicamente permitindo a ocorrência das relações espaciais que dependem da espacialidade fática do mundo e, da maneira como age o ser-no-mundo ao realizar seu projeto existencial (SARAMAGO, 2008).

Por meio da cotidianidade, o ser-no-mundo delineará seus diferentes modos de ocupação do espaço, no qual estão dispostos os entes com os quais se ocupa, ou seja, os entes intramundanos, irá familiarizar com novos fenômenos, pondo em movimento seu existir e projetando-se compreensivamente sobre tal espaço (HEIDEGGER, 2003).

Ser-aí e ser-no-mundo, são equivalentes ao termo existência, assumindo um sentido espacial disposto a "dizer a relação do ser à essência do homem e a relação desta abertura do ser, relações por um lado inacessíveis sem o deslocamento e a redução da consciência da qual é impossível aceder às coisas no seu próprio ser, isto é, na sua mundaneidade" (FRANCK, 1998, p.21). O ser-aí está inserido em um mundo desde sempre compartilhado por outros seres-aí, em meio a outros entes que se mostram. A partir do mundo interpreta-se, compreende a si, existe de maneira própria ou imprópria, se ocupa com outros entes, etc.

Nesse sentido, torna-se adequado mencionar Heidegger (2003, p.114) que nos esclarece:

\footnotetext{
A demonstração fenomenológica do ser dos entes que se encontram mais próximos faz-se pelo fio condutor do ser-no-mundo cotidiano, que também chamamos de modo de lidar no mundo com o ente intramundano. Esse modo de lidar já se sempre se dispensou numa multiplicidade de modos de ocupação.
}

Será por meio da cotidianidade do ser-no-mundo, que os diferentes modos de ocupação do espaço serão moldados, constituídos pelo encontro com diferentes entes com os 
quais se ocupa (HEIDEGGUER, 2003). Será no mundo não compreendido como uma mera realidade física, com dimensões quantificáveis, limites que podem ser descritos, analisados e dispostos em diferentes estudos científicos que o ser-aí se lança compreensivamente delineando suas relações e colocando em movimento seu existir.

Esse espaço pensado por Heidegger vai para além disso. Enquanto um existencial do ser-aí corrobora para que possa atribuir sentido a existência. Silva (2007) enfatiza que: "o espaço se revela na existência, no que existe mundo, que existe ser-aí. E isso, só ocorre porque a compreensão do espaço do ser-aí é simultânea a compreensão de seu próprio ser". O ser-aí é abertura que desencobre o espaço, "trazendo-o a luz em seus modos de manifestação, e assim, os demais entes tornam-se, então próximos ou distantes, no que são espacialmente encontrados" (SILVA, 2007, p.126)

O mundo para o ser-aí é compreendido como o espaço em que se realiza fenomenológica e existencialmente, de acordo com suas orientações e projetos a serem concretizados. O ser-aí não se encontra dentro ou fora do mundo porque ele o espacializa vivendo uma experiência originária em relação ao mundo, por isso, para se referir a esse fenômeno Heidegger utiliza a expressão espacialidade ${ }^{2}$. Enquanto os demais entes estão apenas dispostos no mundo, sendo destituídos de mundo, o ser-aí abre o mundo, os espacializa, libera estes entes fazendo uso deles.

Para Kahlmeyer-Mertens (2015, p.85-86) o ser-no-mundo é um existencial, portanto:

Isso significa que ser-no-mundo integra o todo estrutural (=existencialidade) do seraí ao passo em que este existe. Ser-no-mundo é o existencial que indica como o seraí é no espaço constitutivo do mundo e, em verdade, é enquanto ser-no-mundo que já sempre encontramos o ser-aí, isso quer dizer que ser-aí é sempre no aí do que o mundo constitui. Tal como advertimos que sobre o fato de o ser-aí não deve ser interpretado como um ente dado de antemão, alertamos agora que também não devemos tomar o mundo como um lugar empiricamente constituído, ou, dizendo categoricamente: o mundo não é um local físico onde o ser-no-mundo estaria alocado ou de alguma forma contido. Assim, o laço de ser-no-mundo com seu mundo não é - em absoluto - uma relação de continente e conteúdo, isso porque mundo é, antes, um espaço fenomenal intencionalmente aberto.

O ser-aí é sempre no mundo, é um ser-lançado-em-um-mundo que lhe é familiar, compreende-o e mantém sua existência nesse espaço ontológico que lhe permite tomar consciência de si, a partir de si mesmo, afinal para "se ver o mundo é, pois necessário

\footnotetext{
2 Todas às vezes em que a palavra espaço aparece em meio as discussões ontotológicas-existenciais, estará apontando para a espacialidade, ou seja, essa experiência originária do ser-aí em relação ao mundo pensada por Heidegger.
} 
visualizar o ser-no-mundo cotidiano em sua sustentação fenomenal” (HEIDEGGER, 2003, p.113).

Os nexos referenciais delineados no mundo permitem ao ser-aí por a mostra sua significatividade, ou seja, um "entrelaçamento de significações, do qual é inseparável o mundo circundante, cujo âmbito é espacial, mas não num sentido métrico, como um aposento em que me movimento familiarmente, tal paragem em que me encontras" (NUNES, 2010, p.16).

O ser-no-mundo em seu contexto fático, apresenta familiaridade com o mundo em que executa sua existência, ocupando-o, atribuindo a esse espaço constitutivo um caráter próprio, afinal ele é seu horizonte significativo de realização. Os diferentes modos de ocupação são determinantes para a execução dos “[...] projetos existenciais vindo a ser o ente que é na medida de suas possibilidades” (KAHLMEYER-MERTENS, 2015, p.88).

$\mathrm{O}$ aprofundamento de tais reflexões pode ser encontrado no $\$ .22$ da obra Ser e tempo, no qual Heidegger discute fenomenológicamente o espaço na forma de espacialidade. Afirma que nele o ser-aí se vincula ontológicamente sendo o campo de jogo do ser-no-mundo que somos, nos permitindo lançar-se para as inúmeras possibilidades do seu existir. Enquanto possuidor de estrutura existencial, o espaço emerge como algo próprio ao ser-aí. Heidegger (2013, p.158) salienta sobre isto que:

\footnotetext{
Ao atribuirmos espacialidade ao ser-ai, temos evidentemente que conceber este "serno-espaço" a partir do seu modo de ser. Em sua essência, a espacialidade do ser-aí não é um ser simplesmente dado e, por isso, não pode significar ocorrer em alguma posição do "espaço cósmico" e nem estar a mão em algum lugar. Ambos são modos de ser desse ente que vêm ao encontro dentro do mundo. O ser-aí está e é "no" mundo, no sentido de lidar familiarmente na ocupação com os entes que vem de encontro dentro do mundo.
}

Nessa passagem textual, Heidegger nos apresenta uma experiência fenomenológicoexistencial do espaço superando a compreensão elaborada pelas ontologias regionais. Ao descrever o espaço como um existencial do ser-aí, cujas significações contribuem para o delineamento do sentido a este ente, ressalta a necessidade de não compreendê-lo utilitariamente, por meio de suas delimitações físicas e métricas, como apenas um ente simplesmente dado como objeto de uso, produção e propriedade.

O ser-aí é espacial em sentido originário, afinal não existe ser-aí sem espaço, nem espaço sem ser-aí. Este ente é o único que "abre o mundo", que está-no-mundo e é-no-mundo 
descobrindo-o na medida em que engendra sua existência, portanto, o ser-aí é espacial em sentido originário, cotidianamente sua ação espacializante modela-o. Segundo Heidegger (2013, p.167):

[...] Por mostrar-se essencialmente num mundo, o espaço não decide sobre a modalidade de seu ser. O espaço não precisa ter o modo de ser espacial do que se acha à mão nem o modo de algo simplesmente dado. $\mathrm{O}$ ser do espaço também não possui o modo de ser do ser-aí. Porque o próprio ser do espaço não pode ser concebido como res extensa, não se segue que deva ser determinado ontológicamente como "fenômeno" destas res - na verdade, ele não seria dela distinto - nem que o ser do espaço pudesse ser equiparado ao da res cogitans e compreendido como puramente subjetivo, mesmo que se desconsiderasse toda a problemática referente ao ser desse sujeito.

O ser-aí é espacial por natureza, afinal é "[...] um ente que funda todos os seus comportamentos em relação aos entes em geral em um comportamento originário em relação ao mundo" (CASANOVA, 2009, p. 92). Desse modo, a espacialidade permite ao ser-aí superar a dualidade trazida pela tradição em que homem e mundo se encontram dissociados. Heidegger deixa claro que ambos constituem um ao outro.

O espaço é continuamente construído associado à consciência humana, com múltiplas especificidades que, também, são resultados da temporalidade a que o ser-aí está sujeito possibilitando a vivência de significados específicos ao habitar, ou seja, ao ser-(estar)-nomundo.

A compreensão fenomenológica-existencial permite elucidar que os estudos nos quais o espaço abrange apenas a dimensão territorial são insuficientes, pois as experiências e sentidos constitutivos do projeto existencial desse ser-no-mundo acabam não sendo consideradas. De forma clara, percebe-se que o "homem está envolto de espaços vividos, está também envolto de outros homens que percebem outros espaços de maneira diferente. Perceber, além de significar é dar valor" (DUARTE e MATIAS, 2005, p.194).

Heidegger nos mostra a necessidade de pensar o espaço para além de sua dimensão física, social, constituído por fronteiras políticas ou naturais, transformado pela técnica e pelas necessidades do ser humano, afinal ele é horizonte para a interpretação e compreensão do ser, possuindo uma vinculação ontológica que permite ao ser-aí e mundo formarem-se mutuamente. (LEITE, 2013).

Destaca-se que espaço em Ser e tempo é espacialidade que, por sua vez, implica no modo como o ser-aí sempre experiencia o espaço, um existencial do ser-aí, ou seja, seu 
elemento constitutivo ontológico-existencial. O espaço constitui o ser-aí, lhe é próprio e, permite experimentar o mundo espacialmente. $\mathrm{O}$ mundo também é um espaço constitutivo do ser-aí, seu local de realização.

Em suma, espaço e mundo são compreendidos por Heidegger como nuances de um mesmo fenômeno, parecendo mostrar camadas desse fenômeno, no qual a existência ocorre fazendo emergir o caráter ontológico-existencial testemunhado pelo ser-aí que sou, o ser que é possibilidade, a existência que é minha e os diferentes modos do ser.

\section{CONSIDERAÇÕES FINAIS}

A breve exploração sobre o conceito de espaço tendo como referencia a visão tradicional e a compreensão heideggeriana apresenta na obra Ser e Tempo, nos permite a apresentação de diferenças significativas no modo como ele é apresentado em estudos diversos elaborados ao longo dos últimos séculos.

Podemos afirmar que as ontologias regionais atribuem-lhe dimensões que podem ser mensuráveis, medido, quantificado, delimitado por fronteiras, pelos fatos históricos que lhes são inerentes, pelas transformações ocasionadas pelos processos de industrialização e urbanização, dentre outros fenômenos intrínsecos apresentados em estudos científicos relevantes, mas que ainda, encontram-se no âmbito ôntico, estando a um passo da experiência ontológica fundamental.

Ressalta-se que não se quer questionar a validade científica, tampouco as inúmeras contribuições de tais estudos, apenas ilustrar o quanto as análises de Heidegger podem contribuir para o avanço dessas reflexões, afinal, de maneira fenomenológica existencial o espaço é tratado como um elemento ontológico constitutivo do ser-aí. Este, ao lhe espacializar o experimenta fenomenalmente, põe em movimento seu projeto existencial, a possibilidade de poder ser e os sentidos constitutivos de sua existência demarcada temporalidade.

Ser-aí e espaço não são dois entes distintos como as ontologias o apontam, pelo contrário, como esclarece Heidegger o ser-aí é o próprio mundo espacial, uma vez que, o mundo é espacial apenas porque o ser-aí também o é. Logo, a compreensão do espaço como uma mera base física que pode ser definida por meio de demarcações distintas como propõe a tradição, acaba sendo insuficiente para explicar a amplitude da existência do ser-aí e de sua temporalidade frente ao espaço. 


\section{REFERÊNCIAS}

BOLLNOW, Otto Friedrich. O homem e o espaço. Trad. Aloísio Leono Schmid. Curitiba: UFPR, 2008.

CASANOVA, Marco Antonio. Compreender Heidegger. Petrópolis, RJ: Vozes, 2009.

A falta que Marx nos faz. Rio de Janeiro: Via Verita, 2017 DUARTE, Matusalém de Brito; MATIAS, Vandeir Robson da Silva. Reflexões sobre o espaço geográfico a partir da fenomenologia. Caminhos de Geografia 17 (16), p. 190-196, out $/ 2005$.

FRANCK, Didier. Heidegger e o problema do espaço. Trad. João Paz. Lisboa: Instituto Piaget, 1998.

HEIDEGGER, Martin. Ser e tempo. Trad. Marcia Sá Cavalcante Schuback. Petrópolis: Vozes, 2013.

KAHLMEYER-MERTENS, Roberto S. 10 lições sobre Heidegger. Petrópolis: Vozes, 2015.

INWOOD, Michael. Heidegger. São Paulo: Edições Loyola, 2004

LEITE, Marcela Barbosa. Heidegger e o fundamento ontológico do espaço. In: Diálogos Revista de Estudos Culturais e da Contemporaneidade - N. ${ }^{\circ} 8$ - Fev./Mar., 2013.p.178-195

PASQUÁ, Herve. Introdução à leitura do Ser e Tempo de Martin Heidegger. São Paulo: Instituto Piaget, 2015.

SARAMAGO, Ligia. A topologia do ser: lugar, espaço e linguagem no pensamento de Martin Heidegger. Rio de Janeiro: PUC-RJ; São Paulo: Loyola, 2008.

SILVA, Antonio A. R. da. Relação entre espaço e lugar no pensamento de Martin Heidegger. Revista eletrônica Correlatio, n., Julho de 2007, p.124-138. 